\title{
Childhood Asthma Control Test: a study of the psychometric properties
}

\author{
Childhood Asthma Control Test: estudo das propriedades psicométricas \\ Childhood Asthma Control Test: estudio de las propiedades psicométricas
}

Andreia Filipa de Sousa Félix*iD; Bruno Acácio Branco da Rocha Lopes**iD; Maria Adriana Pereira Henriques***iD; Maria de La Salete Rodrigues Soares**** (D)

\begin{abstract}
Background: The international guidelines recognize that the treatment of asthma focuses both on the current control and the risk of exacerbations, based on the management of symptoms which advocate an objective assessment. The Childhood Asthma Control Test (c-ACT) tool allows an assessment of the control of asthma in children and is used in Portugal, but has no validation.

Objective: To evaluate the psychometric properties of the c-ACT tool for the Portuguese population.

Methodology: A methodological, quantitative, and transversal study, on a sample of 60 children and healthcare providers, for the analysis of the psychometric properties of a measuring tool, written in Portuguese. The internal consistency was evaluated by Cronbach's alpha, and the factorial validity and reliability of the model were analyzed using exploratory factorial analysis.

Results: The tool showed internal consistency, with a Cronbach alpha of 0.716 . There are statistically significant correlations between each item and the overall evaluation.

Conclusion: The c-ACT tool demonstrated good psychometric properties, giving validity and reliability for use in the Portuguese population.
\end{abstract}

Keywords: asthma; child; caregivers; evaluation of symptoms; validation studies

\section{Resumo}

Enquadramento: As diretrizes internacionais reconhecem que o tratamento da asma reside no controlo atual e no risco de exacerbaçóes, sendo estes baseados na gestấo de sintomas que preconiza uma avaliaçáo objetiva. O instrumento Childhood Asthma Control Test (c-ACT) permite uma avaliaçáo do controlo da asma nas crianças, sendo utilizada em Portugal, mas náo apresenta validação.

Objetivo: Avaliar as propriedades psicométricas do instrumento c-ACT para a populaçáo portuguesa.

Metodologia: Estudo metodológico, quantitativo e transversal, numa amostra de 60 crianças e prestadores de cuidados, para análise das propriedades psicométricas de um instrumento de medida, escrito em português. A consistência interna foi avaliada mediante o alfa de Cronbach e a validade fatorial e a fiabilidade do modelo foram analisadas com análise fatorial exploratória. Resultados: $\mathrm{O}$ instrumento demonstrou consistência interna, com alfa de Cronbach de 0,716. Existem correlaçóes estatisticamente significativas entre cada item e a avaliação global.

Conclusáo: $\mathrm{O}$ instrumento c-ACT demonstrou boas propriedades psicométricas, fundamentando validade e fiabilidade para utilizaçáo na populaçáo portuguesa.

Palavras-chave: asma; criança; cuidadores; avaliação de sintomas; estudos de validaçáo

*MSc., Ph.D. Student in Nursing, University of Lisbon. Research and Development Unit in Nursing (UI\&DE), Local Health Unit of Alto Minho, 4950-215, Monção, Portugal [andreiaflipafelix@gmail.com]. (1) https://orcid.org/0000-0001-7740-4124.Contribution to the article: bibliographical research, data collection, statistical treatment and analysis, discussion, writing of the article. Address for correspondence: Avenida Porta do Sol 537, 4950-277, Mazedo, Monção, Portugal.

**MSc., Nurse Specialist in Rehabilitation Nursing Local Health Unit of Alto Minho, 4950-215, * MSc., Nurse Specialist in Rehabilitation Nursing, Local Healh Unit of Al Minho, 4750-215, Monçao, Portugal [bruno.lopes@ulsam.min-saude.pt].(B) htps://orcid.org/0000-0002-41352913. Contribution to the article: data collection, statistical treatment and analysis, discussion. ***Ph.D., Coordinating Professor, Research and Development Unit in Nursing (UI\&DE). orcid.org/0000-0003-0288-6653. Contribution to the article: research design conception, discussion, revision and approval of the final version of the article.

****Ph.D., Associate Professor, UICISA, Polytechnic Institute of Viana do Castelo, School of Health, 4900-314, Viana do Castelo, Portugal. [saletesoares@ess.ipvc.pt]. (D) https://orcid.org/0000-0003-3582-044X. Contribution to the article: research desion conception, statistical treatment and analysis, discussion, revision and approval of the final version of the article.

\section{Resumen}

Marco contextual: Las directrices internacionales reconocen que el tratamiento del asma reside en el control actual y en el riesgo de exacerbaciones, que se basan en una gestión de los síntomas que aboga por una evaluación objetiva. El instrumento Childhood Asthma Control Test ( $c-A C T)$ permite una evaluación del control del asma en nińos, y se utiliza en Portugal, aunque no está validado.

Objetivo: Evaluar las propiedades psicométricas del instrumento c-ACT para la población portuguesa.

Metodología: Estudio metodológico, cuantitativo y transversal, en una muestra de 60 niños y cuidadores, para analizar las propiedades psicométricas de un instrumento de medición escrito en portugués. La consistencia interna se evaluó utilizando el alfa de Cronbach, mientras que la validez factorial y la fiabilidad del modelo se analizaron mediante un análisis factorial exploratorio.

Resultados: El instrumento demostró consistencia interna, con el alfa de Cronbach de 0,716. Existen correlaciones estadísticamente significativas entre cada ítem y en la evaluación general.

Conclusión: El instrumento c-ACT demostró buenas propiedades psicométricas, y proporciona validez y fiabilidad para su uso en la población portuguesa.

Palabras clave: asma; niño; cuidadores; evaluación de síntomas; estudios de validación 


\section{Introduction}

Asthma is the most common chronic disease in childhood, manifesting itself through persistent symptoms, such as a feeling of shortness of breath, chest tightness, wheezing, and coughing. It may present irregular and unpredictable symptomatic episodes (Global Initiative for Asthma [GINA], 2018) and is one of the main causes of school absenteeism (Everhart, Miller, Leibach, Dahl, \& Koinis-Mitchell, 2018) and hospitalization (Direção-Geral da Saúde [DGS], 2014a). It is considered a complex disease because it can depend on several multilevel factors. The nature of these factors and their inter-relationships are not well understood and may, thus, have an impact in several areas, including the physical, the psychological, the social, and family (Wood, Miller, \& Lehman, 2015).

The policies of GINA (2018) and the National Asthma Education and Prevention Program (NAEPP, 2007) acknowledge that the objective of asthma treatment focuses on two components: the current control and the future risk of exacerbations. We can assume that the current control of asthma consists in "the extent to which the manifestations of asthma are minimized by therapeutic interventions, that is, the degree to which the therapy goals are met" (NAEPP, 2007, p. 25). In Portugal, the National Program for Respiratory Diseases (DGS, 2014a), in line with the guidelines of GINA (2018), aims to achieve not only a harmonized asthma management for the delineation of an early diagnosis, but also the necessary education of the child and the healthcare provider, the efficient use of therapy to aid in the control of the disease, and also the existence of surveillance, rehabilitation, and monitorization procedures of the disease integrated management.

Aiming at the management of symptoms, an "accurate assessment and objective monitoring of asthma, with multidimensional, simple, and relatively short and easy-to-use tools," becomes decisively necessary, as shown by the Childhood Asthma Control Test (Alzahrani \& Ellen A Becker, 2016, p. 113). It allows a quantitative, simple, and fast self-evaluation of asthma by the child and the healthcare provider and is internationally recommended by GINA (2018) and in Portugal by the General Directorate of Health
(DGS, 2014b). The absence of a tool based on psychometric studies for the evaluation of symptoms of children with asthma, also keeping in mind the healthcare provider, motivated the implementation of this research. Thus, the objective of this study is the evaluation of the psychometric properties of the c-ACT tool for the Portuguese population. The purpose is to contribute to symptoms management focused on children with asthma and their healthcare provider, providing a potentially facilitating tool for objective assessment that might be used, within the context of clinical practice and at home, by children with asthma, aged between 6 and 11 years, and their healthcare provider, the target population of this study.

\section{Background}

The quality of care provided to children with asthma involves the diagnosis and initial treatment to achieve disease control, the prevention of exacerbations, and also long-term intervention (GINA, 2018). In this perspective, the effective asthma management requires the development of a partnership between the child, the healthcare provider, and the health professional, to promote a more excellent knowledge about the disease, responsibility, confidence, and skills to assume an essential role in its management, this being a "very important therapeutic practice for asthmatics" (Cano-De La Cuerda, Useros-Olmo, \& Muñoz-Hellín, 2010, p. 601). The c-ACT tool was developed with the purpose of building a "simple tool of reliable measurement to evaluate the control of asthma in children" (Liu et al., 2007, p. 818). It was built for children between ages 4 and 11, being a self-completion questionnaire integrating the perspectives of both the child and the healthcare provider, with the goal of capturing the "multidimensional nature" which is necessary for the management of symptoms (Liu et al., 2007 , p. 818). The evaluation of symptoms in children is also an unique stimulus, because they "may be unaware of the symptoms, unable to verbalize the symptoms of asthma or recall the information of symptoms", and an inadequate assessment of their intensity can lead to an underestimation of asthma severity, which may influence the strategies of symptoms 
management (Yawn, Brenneman, Allen-Ramey, Cabana, \& Markson, 2006, p. 324).

This tool, developed in the United States of America by Liu et al. (2007), consists of two parts, with a total of seven items, a Likerttype scale, which assesses the level of control of asthma in the previous 4 weeks. The first part, intended for completion by the child is composed of four questions, with four answer options each, accompanied by a representative image of the face of a child, on the perception of asthma control; the limitation of activities; daytime symptoms and nocturnal awakening, without specific time limit for answering. The second part of the tool, for completion by the healthcare provider, is constituted by three questions, with six answer options each, are questions about the symptoms in the daytime, during the night and on the respiratory sounds, referring to a period of 4 weeks. The findings of clinical validity, for this tool, demonstrate that it can distinguish between several levels of symptoms control, being consistent with the guidelines of GINA and also takes into account the parameters of evaluation of pulmonary function (Sasaki et al., 2015).

The total score of the instrument is obtained by the sum of the response of all items, which can be between 0 and 27. In the first publication of the instrument, 19 was considered the cutoff point, that is, scores between 0 and 19 points indicate inadequate control of the disease (Liu et al., 2007). On a later occasion, and with the aim of assessing the validity of contents, the interpretation of the score of the instrument was optimized, making it sensitive to the GINA guidelines (2018), more specifically to the degree of control of the disease defined (controlled, partially controlled and non-controlled). So, nowadays, the evaluation of asthma control considers the following classification: results of 0 to 12 are considered uncontrolled asthma; from 13 to 19 they are considered to be partially controlled asthma; from 20 to 27 they are considered to refer to controlled asthma. This way, two cutting points, are distinguished, (Liu et al., 2010). However, even though, through a score, this tool has the ability to classify the degree of control of asthma, it is not sensitive to the occurrence of exacerbations, future risks and decline in pulmonary function (Koster et al., 2011; Wu,
Tantisira, Li, Schuemann, Weiss, \& Fuhlbrigge, 2011).

Given that it can be used in different contexts (clinical practice and homecare), owing to its accessibility and simplicity of completion, this instrument has the potential to improve communication on the management of asthma symptoms between the child and the healthcare provider, providing also a complete picture of the level of control for health professionals.

\section{Research Question}

Does the Portuguese version of the c-ACT have reliable psychometric properties to submit the evaluation of asthma control in children, between 6 and 11 years of age?

\section{Methodology}

This study, of a methodological nature, is a quantitative and transversal approach. The sample, non-probabilistic by convenience, was composed of children with asthma and their caregivers, belonging to six counties of Alto Minho, followed in the context of primary health care. The criteria for inclusion in the sample were defined as follows: a) Children between 6 and 11 years of age, with a diagnosis of asthma (medical diagnosis performed by encoding in the clinical process) for the last 6 months at least, with a prescription for treatment of symptomatic relief; not presenting other co-morbidities besides asthma; b) Healthcare providers, older than 18 , to children who matched the criteria defined above, with reading and writing skills; and agreeing to participate in the study, along with the child. The sampling technique for the selection of participants was non-probabilistic by convenience. The sample size calculation was based on the existence of 15 observations for each variable (Marôco, 2014). Given that the accessible population was small $(n=67)$ we have resorted to Raosoft Platform, where for an estimated error of $5 \%$, with a confidence interval of $95 \%$, the recommended sample was 58 observations. So, considering the two indications, we opted for a sample of 60 children and healthcare providers. The research team carried out the 
data collection between September 2017 and March 2018.

The data were organized and analyzed using the IBM SPSS Statistics, version 21.0. It started with the descriptive statistical analysis, followed by the analysis of internal consistency, through the Cronbach alpha coefficient, and the study of the construct validation through exploratory factor analysis on major components. We proceeded to the analysis using the Kaiser-Meyer-Olkin (KMO) test to check the adequacy of the data and the factorial analysis and subsequently with the Bartlett test in order to determine the adequacy of the data obtained for the factorial analysis. In the method of principal components, the number of factors to retain was determined using the Kaiser criteria, scree plot, and by the variance extracted per factor. The rotation of factors continued according to the orthogonal rotation method (Varimax) in order to assess the construct validation. The level of significance in the statistical analysis was $5 \%(p<0.05)$.

When planning this research study, authorization for the use of the tool to was requested from the author (Liu et al., 2007) and the pharmaceutical company holding the rights of use, GlaxoSmithKline. The study was also approved by the Ethics Committee for Health of the Local Health Unit of Alto Minho (Opinion $31 / 2017)$. Due to the need for consultation of data of the clinical file of children with asthma, authorization from the National Commission for Data Protection (4377/2017) was requested. As far as the participants are concerned, they were informed of the reasons for the research, its purpose and its goals. A formal document was issued so that care providers and children could formally say they were duly informed and freely participated in the research, with the provision of canceling their participation at any moment. The confidentiality of information and respect for private life was taken into consideration, ensuring anonymity while participating.

\section{Results}

In the sample used, which consisted of 60 observations, the majority of healthcare providers are mothers $(91.7 \% ; n=55)$ aged between 26 and $59(M=39 ; S D=6 \cdot 12)$. As regards work conditions, healthcare providers worked mostly full time $(71.7 \% ; n=43)$, of which $40 \%(n=$ 24) had academic qualifications corresponding to secondary education and others, and $35 \%$ $(n=21)$ completed the 3rd Cycle of Basic Education.

Of the children with asthma, 53\% $(n=32)$ are female and 47\% $(n=28)$ male. The children were between the ages of 6 and $11(M=9 ; S D$ $=1.75)$, as already mentioned in the inclusion criteria. Regarding the disease, the children had asthma for a mean of 5.87 years $(S D=2.6)$, with a mean time of diagnosis performed at 3 years of age $(S D=2.28)$. In what concerns exacerbations of asthma, children presented 4 days $(S D=7)$ of school absenteeism each on average during the last school year, with a mean of one $(S D=2)$ emergency room treatment (in the last 12 months) and with a mean of $1(S D=$ 3) unscheduled consultation with the assistant physician, in the last 12 months.

Given the size of the study sample, we used the Kolmogorov-Smirnov test for analysis of normality. Among the variables studied, the age of healthcare providers follows a normal distribution $(K S=0.095 ; p=0.200)$. However, the number of days of school absenteeism ( $K S$ $=0.296 ; p=0.000$ ), the number of emergency room treatment for exacerbation of asthma in the last 12 months $(K S=0.320 ; p=0.000)$, the number of medical unscheduled consultation in the past 12 months $(K S=0.333 ; p=0.000)$, the number of years of evolution of the disease $(K S=0.128 ; p=0.016)$, and the child's age at diagnosis $(K S=0.134 ; p=0.009)$ did not follow a normal distribution.

From the analysis of the normality of the items that compose the instrument, we found that these do not follow a normal distribution $(p$ $<0.05)$.

The study of tool accuracy, performed by the analysis of internal consistency, allowed to see that the value of Cronbach's alpha coefficient was 0.716 , thus showing adequate levels of inner consistency. In the study of the construction of this tool, Cronbach's alpha coefficient obtained was 0.79 . Validations for other populations obtained similar figures.

Table 1 presents the correlation between each of the tool's items and its global figures, through the Pearson coefficient $(r)$, as well as the $p$-value, 
as to demonstrate the extent of the relationship between two variables. The existence of statistically significant correlations between all items in the tool and their overall figures is evident. However, Item 1, referring to the child, presents a 0.30 correlation. Given the theoretical importance of assessing the child's perception of the disease, its exclusion is not suggested. The remaining items have a correlation of more than 0.42 .

Table 1

Pearson's correlation coefficient between variables and the c-ACT total score

\begin{tabular}{|c|c|c|c|c|c|c|c|c|c|}
\hline & & \multicolumn{4}{|c|}{ Asthmatic child } & \multicolumn{3}{|c|}{ Healthcare provider } & \multirow{2}{*}{ c-ACT } \\
\hline & & Item 1 & Item 2 & Item 3 & Item 4 & Item 1 & Item 2 & Item 3 & \\
\hline \multirow{2}{*}{ c-ACT } & $\begin{array}{l}\text { Pearson's } \\
\text { correlation } \\
\text { coefficient }\end{array}$ & 0.300 & $0.415^{* *}$ & $0.587^{* *}$ & $0.583^{* *}$ & $0.753^{* *}$ & $0.716^{* *}$ & $0.808^{* *}$ & 1 \\
\hline & $\begin{array}{l}\text { Sig. } \\
\text { (2 extremes) }\end{array}$ & 0.020 & 0.001 & 0.000 & 0.000 & 0.000 & 0.000 & 0.000 & \\
\hline
\end{tabular}

${ }^{* *}$ Correlation is significant at the level of 0.01 or lower.

When assessing the psychometric properties of the c-ACT tool, the principal component analysis began with the adaptation of the data to the factorial analysis through the KMO test, with 0.684 (reasonable) as a result. The null hypothesis for the of Bartlett's sphericity test $\left(\chi^{2}=90.025 ; d f=21 ; p=0.000\right)$ is rejected because it has statistical significance. These indicators confirm that the data are adequate to proceed with the factorial analysis. For the

Table 2

Main components analysis

\begin{tabular}{|c|c|c|c|}
\hline \multirow{2}{*}{ Childhood Asthma Control Test } & & \multicolumn{2}{|c|}{$\begin{array}{c}\text { Factors } \\
\text { explained variance \% }\end{array}$} \\
\hline & & $\begin{array}{l}\text { Factor } 1 \\
38.93 \%\end{array}$ & $\begin{array}{l}\text { Factor } 2 \\
16.90 \%\end{array}$ \\
\hline \multirow{4}{*}{ Asthmatic child } & Item 1 & -0.151 & 0.856 \\
\hline & Item 2 & 0.429 & -0.007 \\
\hline & Item 3 & 0.651 & 0.163 \\
\hline & Item 4 & 0.808 & -0.120 \\
\hline \multirow{3}{*}{ Care provider } & Item 1 & 0.424 & 0.686 \\
\hline & Item 2 & 0.590 & 0.403 \\
\hline & Item 3 & 0.795 & 0.240 \\
\hline Cronbach's Alfa & & 0.69 & 0.33 \\
\hline
\end{tabular}

extraction of factors, we used the principal components method, according to the criteria already presented. The choice fell on the orthogonal (Varimax) rotation. Two factors stood out, with a cumulative variance of $55.83 \%$. In Table 2 the two factors extracted are presented, as well as the factorial weighs of each item, especially of the factor to which they belong. Cronbach's alpha calculation is presented for each factor. 


\section{Discussion}

Asthma is the most common chronic disease in childhood (Observatório Nacional de Doenças Respiratórias, 2015) and constitutes a public health problem (DGS, 2014a). It is associated with high morbidity, is responsible for recurrent non-scheduled doctor visits, and constitutes the leading cause of children hospitalization in Portugal (Sais et al., 2013).

The objective of this study was to assess the psychometric properties of c-ACT, in order to facilitate its use in research and clinical practice of nursing, more specifically in the area of rehabilitation nursing. After the application of the tool to a sample consisting of 60 healthcare providers and the same number of children with asthma, we proceeded to the analysis and study of its psychometric properties.

The study of accuracy showed good inner consistency for the totality of the form. We chose this coefficient because it is "the best method to evaluate one of the most important sources of error measurement" (Daniel, Silva, \& Ferreira, 2015, p. 134).

The results obtained by Pearson's correlation coefficient allow us to say that there is a statistically significant correlation between each item of the instrument and its overall value, except the first and second items regarding the child with asthma, which feature lower coefficients, but still statistically significant. However, from a perspective of the critical analysis of results, it is unquestionable that these items should remain in the tool and the order established by its author, given their clinical and practical relevance. This point of view is corroborated by Loureiro and Gameiro (2011), who claim that the statistical significance might not be related to the clinical and educational significance that the item has in the tool.

Regarding the study of the tool validity, we assumed that content validity would have been guaranteed because the author of the instrument had previously carried it out in a study after that of the tool construction. In this transversal and longitudinal study, the author ensures content validity, adapting the cutoff points of the total score (Liu et al., 2010). This content validity is of extreme importance, contributing to the analysis of the child's own needs since the sample of this study shows that $11.7 \%$ of the children $(n=7)$ presented uncontrolled asthma and $53.3 \%(n=32)$ partially controlled asthma. This inadequate control may be "strongly associated with an increased risk of asthma exacerbations," highlighting the need that children and healthcare providers have of controlling asthma, through pharmacological and non-pharmacological interventions inserted in a continuous cycle of assessment, intervention, and review (GINA, 2018, p. 28), with the purpose of achieving the "control of the manifestations of disease" (Hamawandi, Ali, \& Naji, 2016, p. 161).

However, the obtained results, the use of this instrument, and the planning of future researches must take into account the limitations of this study. The non-probabilistic sampling technique by convenience, limited to a geographical area, does not allow extrapolating the results for the population, suggesting, thus, an extended working field in future researches. Despite these limitations, the results obtained allow stating that the tool under scrutiny meets the validity and reliability criteria, essential to the tool's use in a clinical and household context, increasing the relevance of the management of symptoms of children with asthma, which, in addition to the clinical and household use, must be considered for its application in research.

\section{Conclusion}

The complexity of childhood asthma, which correlates with environmental, physiological, and psychosocial factors, implies constant change and adaptation to the needs of the child and his/her family in all its functional areas. The high incidence and prevalence of asthma in children, associated with its chronic and unpredictability nature, lead to its significant impact on healthcare provision, constituting a challenge for nursing intervention, more specifically in the area of rehabilitation. Since nursing is a complex science and asthma is a complex disease, tools that allow an accurate assessment of the degree of asthma control are necessary. They must be multidimensional, accessible, quick, and easy to fill in as c-ACT is. This tool, with its sound psychometric properties, from the perspective of the child and the healthcare provider, has the ability to clarify the level of 
asthma control, thus becoming a significant instrument for symptoms management. Given that $65 \%$ of children with asthma belonging to the sample presented uncontrolled or partially controlled asthma, the analysis of results shows the need for reflection on the priorities and needs of nursing intervention. This is a challenge for the provision of healthcare focused on the child and the healthcare provider. In this context, awareness of the importance of personal autonomy is imperative and is only achieved when dealing with the other person as a human being, in a grounded therapeutic relationship based on negotiation and partnership.

The research answers to the objective outlined. We conclude that c-ACT is a tool that has good psychometric properties and is both valid and reliable for the Portuguese population. However, we recommend conducting further researches with broader samples, examining their properties and widening the research field. We consider that this study alerts for the need for nursing intervention in children with asthma and healthcare providers, and at the same time provides a tool which is simple to use, assesses the control of asthma, and is sensitive to situations of inadequate control.

\section{References}

Alzahrani, Y. A., \& Ellen A Becker. (2016). Asthma control assessment tools. Respiratory Care, 61(1), 106-116. http://doi.org/10.4187/respcare.04341

Cano-De La Cuerda, R., Useros-Olmo, A. I., \& MuñozHellín, E. (2010). Effectiveness of therapeutic education and respiratory rehabilitation programs for the patient with asthma. Archivos de Bronconeumología, 46(11), 600-606. http://doi.org/10.1016/j. arbres.2010.07.003

Daniel, F., Silva, A. G. da, \& Ferreira, P. L. (2015). Contributo para a discussão da avaliação da fiabilidade de um instrumento de medição. Revista de Enfermagem Referência, 4(7), 129-137. doi: http://doi. org/10.12707/riv15003

Direção-Geral da Saúde. (2014a). Doenças Respiratórias em números - 2014 Programa Nacional para as Doenças Respiratórias.

Direção-Geral da Saúde. (2014b). Programa Nacional para as Doenças Respiratórias - Manual para abordagem da sibilância e asma em idade pediátrica. Direção-Geral da Saúde.
Everhart, R. S., Miller, S., Leibach, G. G., Dahl, A. L., \& Koinis-Mitchell, D. (2018). Caregiver asthma in urban families: Implications for school absenteeism. Journal of School Nursing, 34(2), 108-113. doi: http:// doi.org/10.1177/1059840516689326

Global Initiative for Asthma. (2018). Global Strategy for Asthma Management and Prevention. doi: http://doi. org/10.1183/09031936.00138707

Hamawandi, A. M. H., Ali, K. M., \& Naji, A. Z. (2016). Assessment of Asthma Control and Severity among Children According to Global Initiative for Asthma Guidelines in Sulaimani City-Iraq. European Scientific Journal, 12(3), 160-170. doi: http://doi.org/10.19044/ esj.2016.v12n3p160

Koster, E. S., Raaijmakers, J. A. M., Vijverberg, S. J. H., Koenderman, L., Postma, D. S., Koppelman, G. H., ... Maitland-van der Zee, A. H. (2011). Limited agreement between current and long-term asthma control in children: The PACMAN cohort study. Pediatric Allergy and Immunology, 22(8), 776-783. doi: http:// doi.org/10.1111/j.1399-3038.2011.01188.x

Liu, A. H., Zeiger, R. S., Sorkness, C. A., Ostrom, N. K., Chipps, B. E., Rosa, K., ... McDonald, J. (2010). The Childhood Asthma Control Test*: Retrospective determination and clinical validation of a cut point to identify children with very poorly controlled asthma. Journal of Allergy and Clinical Immunology, 126(2), 267-273.e1. doi: http://doi.org/10.1016/j. jaci.2010.05.031

Liu, A. H., Zeiger, R., Sorkness, C., Mahr, T., Ostrom, N., Burgess, S., ... Manjunath, R. (2007). Development and cross-sectional validation of the Childhood Asthma Control Test. Journal of Allergy and Clinical Immunology, 119(4), 817-825. doi: http://doi.org/10.1016/j. jaci.2006.12.662

Loureiro, L. M. de J., \& Gameiro, M. G. H. (2011). Interpretação crítica dos resultados estatísticos: Para lá da significância estatística. Revista de Enfermagem Referência, 3(3), 151-162. doi: http://doi.org/10.12707/RIII1009

Marôco, J. (2014). Análise Estatística com o SPSS Sattistics (6 $6^{\mathrm{a}}$ ed.). Pêro Pinheiro, Portugal: ReportNumber.

National Asthma Education and Prevention Program. (2007). Guidelines for the Diagnosis and Management of Asthma.

Observatório Nacional das Doenças Respiratórias. (2015). $10^{\circ}$ Relatório panorama das doenças respiratórias em Portugal: Caminhos para o futuro.

Sais, C., Martinez, E., Lopes, H., Completo, J., Delgado, M., \& Casas, M. (2013). Ambulatory Care Sensitive Conditions: Impacte do internamento dos doentes crónicos no SNS. IASIST, Dezembro, 41.

Sasaki, M., Yoshida, K., Adachi, Y., Furukawa, M., Itaza- 
wa, T., Odajima, H., ... Akasawa, A. (2015). Factors associated with asthma control in children: findings from a national Web-based survey. Pediatric Allergy and Immunology, 33(10), 804-809. doi: http://doi. org/10.1111/pai.12316

Wood, B. L., Miller, B. D., \& Lehman, H. K. (2015). Review of family relational stress and pediatric asthma: The value of biopsychosocial systemic models. Family Process, 54(2), 376-389. doi: http://doi.org/10.1111/ famp. 12139
Wu, A. C., Tantisira, K., Li, N., Schuemann, B., Weiss, S. T., \& Fuhlbrigge, A. L. (2011). Predictors of symptoms are different from predictors of severe exacerbations from asthma in children. Chest, 140(1), 100-107. doi: http://doi.org/10.1378/chest.10-2794

Yawn, B. P., Brenneman, S. K., Allen-Ramey, F. C., Cabana, M. D., \& Markson, L. E. (2006). Assessment of asthma severity and asthma control in children. Pediatrics, 118(1), 322-329. doi: http://doi.org/10.1542/ peds. 2005-2576 